\title{
Water and Wastewater Systems in Highly Energy-Efficient, Environmentally Friendly Houses for 2013 Solar Decathlon China FENG Shi ${ }^{1,}$, , WEI Wang ${ }^{2, b^{*}}$ and BENBIN Zhang ${ }^{3, c}$

\author{
${ }^{1}$ School of Architecture and Civil Engineering, Xiamen University, Xiamen 361005, China \\ ${ }^{2}$ School of Architecture and Civil Engineering, Xiamen University, Xiamen 361005, China \\ ${ }^{3}$ School of Energy Research, Xiamen University, Xiamen 361102, China

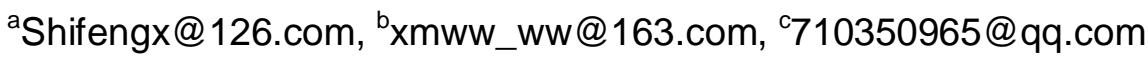

Keywords: Water system; Wastewater system; Solar Decathlon; Energy-Efficient houses.

Abstract. This paper discusses the design of water and wastewater systems in highly energy-effi' cient, environmentally friendly houses for 2013 Solar Decathlon China (SDC). Team XIAU's work "Sunny Inside" is taken as an example to discuss the design and installation of cold and hot water systems, grey water and rainwater collection systems, irrigation system and drainage system. Heat pump, solar water heater, low-pressure air atomization and membrane biological reactor are introduced. Other teams' new technologies on this issue are also being discussed.

\section{Introduction}

The Solar Decathlon (SD) is an intenational competition that challenges collegiate teams to design, build and operate solar-powered houses that are cost-effective, energy-efficient and attractive. As future houses, they also need to be environmentally friendly. SD is part design contest, part science fair, and part public service [1]. 2013 Solar Decathlon China(SDC) was hosted in Datong with 22 teams participants from 35 universities in autumn. Water and wastewater systems are very important for a house, so as for the competition. In a house that is environmentally friendly and highly energy-efficient, there will be supply water treatment and wastewater treatment including cold water system, hot water system, grey water system and so on. This paper mainly takes team XIAU (Xiamen University, China)'s work "Sunny Inside" for example. Other teams' houses are also introduced. Fig. 1 shows the appearance of "Sunny Inside".

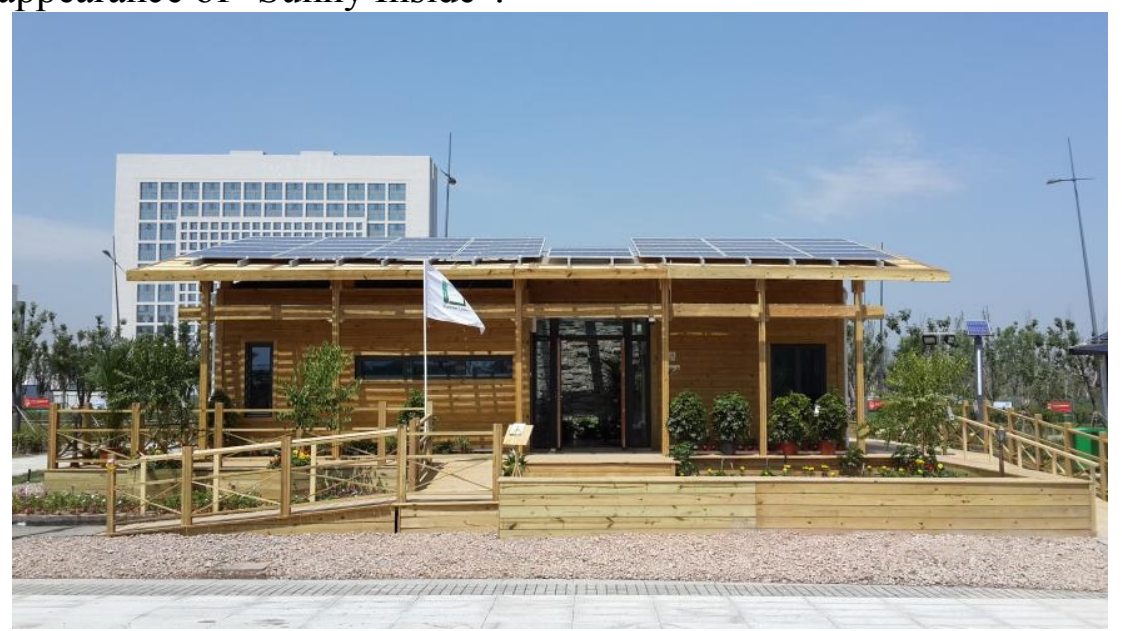

Fig. 1 Team XIAU's house "Sunny Inside"

On the one hand, water is the source of life. How to deal with water and wastewater in a house effects the people's life quality. On the other hand, a future house must be environmentally friendly and energy efficient. Therefore, water and wastewater systems should be designed carefully and considerately. There should be cold and hot water systems to supply the daily water, grey water collection system to collect and disposal the grey water, rainwater collection system to collect and disposal the rainwater, irrigation system to water the plants and drainage system to drain the water which can not be reused. The parameters of the equipments such as solar water heater, pumps and 
valves that need electricity should be exactly calculated to choose the right type to avoid extra energy waste. Materials and sizes of pipes in different systems also need to be chosen respectively. In general, "suitable" is the first rule to choose equipments and pipes.

\section{Supply Water Treatment}

All the water in the house comes from the main supply water pipe, which was given on the competition site of SDC. The first thing to do is bringing water into the house. The main supply water pipe was made of PE and its diameter was $50 \mathrm{~mm}$. If the diameter wasn't fit to designed pipes, a reducer union was needed.

Cold Water System. Before designing water and wastewater systems, the floor plan of a house have to be done. The floor plan of Sunny Inside is shown in fig. 2. According to the floor plan, cold water mainly went into kitchen for washbasin and dishwasher, bathroom for washbasin, clotheswasher and shower (Closestool wasn't connected according to rules of SDC), and equipment room for solar water heater.

Team UTM form Malaysia used a filter in their house to clean the supply water before it went into the house. Then the filtered water went into a big black cold water tank on the roof supplying water to the house. The filter can make cleaner water, but it is not necessary. The quality of municipal water in China is OK for daily use. On the other hand, the filter reduces water pressure which adds difficulty to use the filtered water.

Team XIAU's cold water pipes were all PPR pipes with diameters $20 \mathrm{~mm}$ and $25 \mathrm{~mm}$. Main pipe's diameter was $25 \mathrm{~mm}$ and branch pipe's was $20 \mathrm{~mm}$. They used T-junction, angle coupling and straight joint to connect the cold water pipes by hot welding machine. Most of the cold water pipes were placed under the house, the only way to get into the house was going up through holes of floor which were punched in advance by hole punching machine. For this reason, the exactly location of washbasin, dishwasher, clotheswasher and shower had to be marked out on drawings or on floor directly. Clotheswasher, dishwasher and cooking accounted for 60 points in SDC, which were related to the water systems.

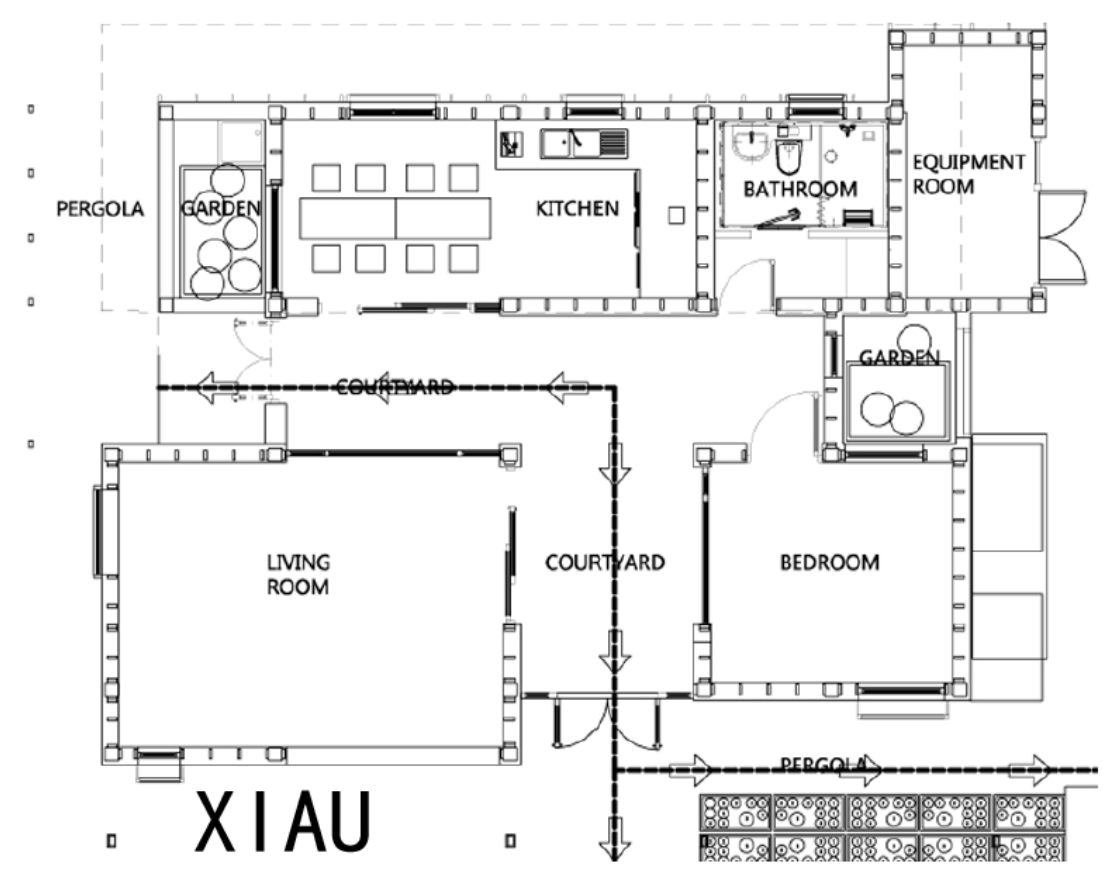

Fig. 2 Floor plan of Sunny Inside

Hot Water System. Water heating accounts for $17 \%$ of all residential site energy use in the United States, making it the third largest use of energy in homes [2]. Therefore, Hot water is always one of the ten scoring items, which accounts for 10 percent proportion in the total one thousand points of SD. Because of that, every team had a solar water heater and dealt with hot water very seriously. In SDC, 
there were 16 draws of hot water. As rules said, for each draw, at least $60 \mathrm{~L}$ of hot water would be delivered in no more than 10 minutes to qualify for points, which was easy to reach. But there were other things, only when delivering an average temperature of at least $45^{\circ} \mathrm{C}$, could all available points be earned. The maximum number of hot water drew for one day would not exceed three, but they might occur consecutively.

In order to get full points, hot water tank should be big enough in case of three consecutive draw. The volume of team XIAU's hot water tank was 260L. Team XIAU's solar water heater is shown in fig. 3. There was a heat pump connected with hot water tank and flat plate solar collector to heat water with the consuming of electricity working only when the temperature of water in tank could not be heated to reach $60^{\circ} \mathrm{C}$ by solar energy. Hot water finally went into kitchen and bathroom to supply washbasins, dishwasher and shower. Compared to directly electric water heater, heat pump can save $70 \%$ consumption of electricity annual mean because of its high efficiency. Schematic of a simplified heat pump water heater (HPWH) system is shown in fig. 4. The HPWH removes heat from the ambient air and puts it into a water storage tank. This process produces cooler, dryer (depending on relative humidity) exhaust air than the source air. Therefore, placement of the HPWH relative to the conditioned space affects overall building energy use [2].
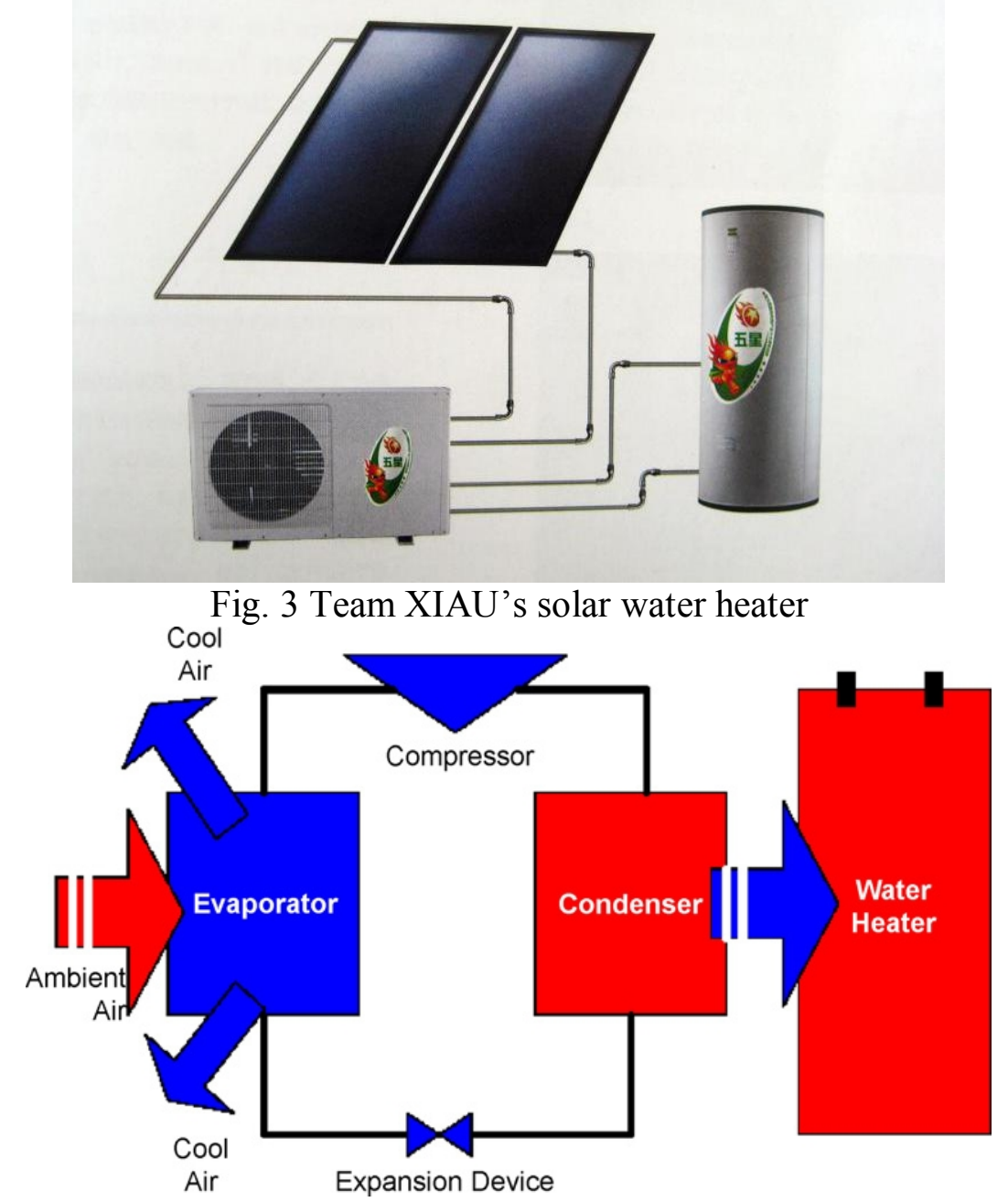

Fig.4 Schematic of a simplified HPWH system [3]

Fig. 5 shows team ISRAEL's hot water system including three water tanks, in which, the big green water tank was hot water tank, the smallest tank was cold water tank to supply water to heat, the middle tank was regulating tank to protect hot water tank from overheating. This system was connected to air conditioner which could use both water circulation and electricity at the same time to adjust the temperature indoor. According to the design, team ISRAEL's hot water system and air conditioner will save more energy than team XIAU, but their systems are more complicated occupying such big space. 
Team NJHA located 3 sets of 12 solar tubes on the south façade of their house which is shown in fig. 6. This allowed solar energy in the form of heat to be efficiently captured. The heat could be used to pre-heat domestic water for use by the house occupants or to heat water for use in the radiant floor. By using the sun's energy directly - the radiant flooring system would significantly reduce the strain on the air handler, as well as eliminate fossil fuel consumption related to heating. Their design was exquisite to use solar energy for heating floor which was really necessary in cities like Datong in cold winter. And their energy balance was better than these houses using air conditioners to keep warm indoor in winter.

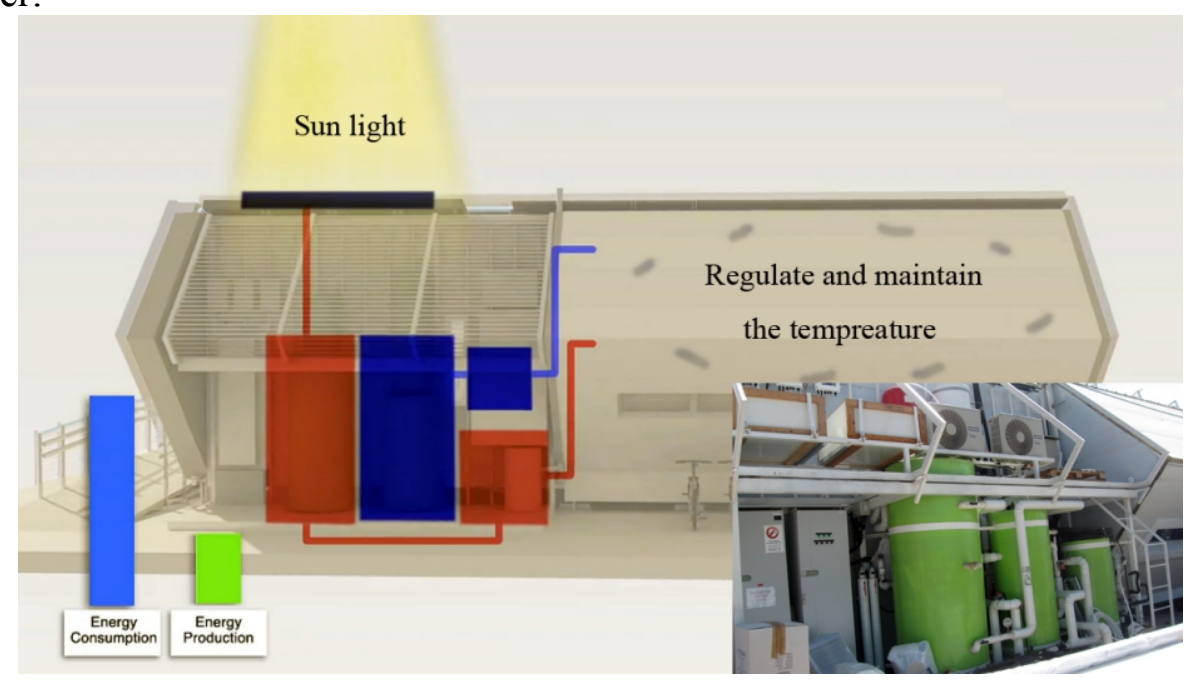

Fig. 5 Team ISRAEL's hot water system

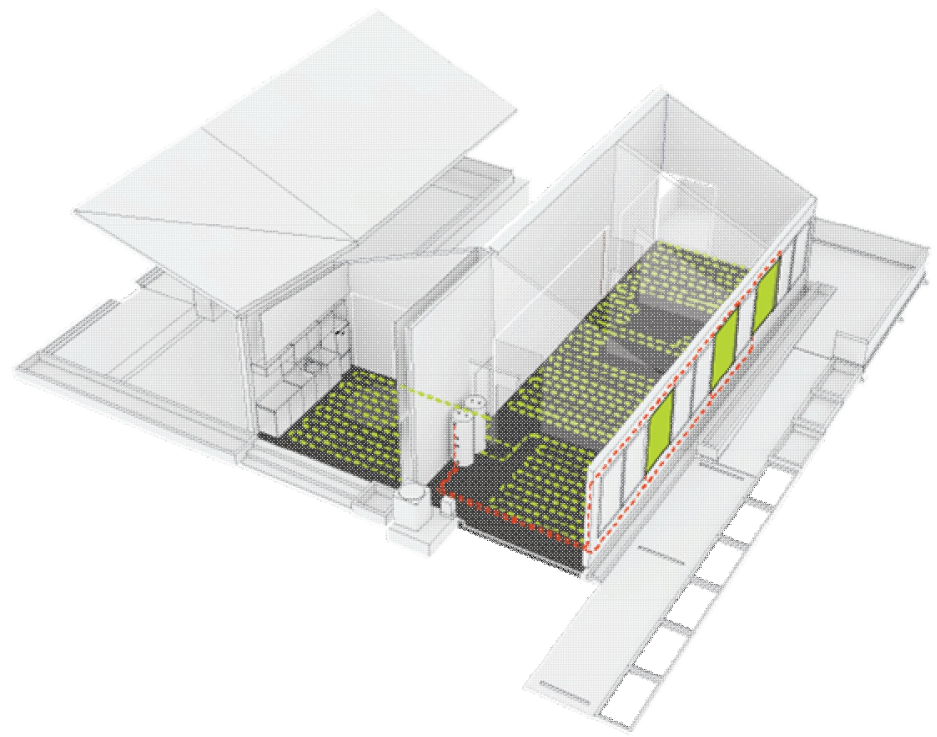

Fig. 6 Team NJHA's hot water system

\section{Wastewater Treatment}

The main drainage pipe was given on the competition site of SDC. Team XIAU drained dirty wastewater and collected the relatively clean grey water to dispose for irrigation. Rainwater was also collected to a rainwater tank for irrigation.

Grey Water Collection System. Wastewater from dishwasher, clotheswasher, and the washbasin in kitchen was dirty which made the reuse of water difficult, on that account, team XIAU drained the dirty water. And the relatively clean wastewater which was called grey water from shower and the washbasin in bathroom was collected to a grey water tank after being disposed by a membrane biological reactor (MBR), which is shown in fig. 7. Fig. 8 shows schematic diagrams of basic MBR configurations. In this figure, a suction force is applied to draw the water through the membrane, 
while the sludge is retained on the membrane surface. A manifold at the base of the reactor diffuses compressed air within the reactor, providing oxygen to maintain aerobic conditions. The air bubbles also function to scour the membrane surface and clean the exterior of the membrane as they rise in the reactor[4]. Team NUS used a more traditional way to deal with the grey water as is shown in fig. 9 . Their equipment was four layers of sand and stones to filter the grey water, which could only wipe off large particle pollutants in the water. But it's cheaper than team XIAU's equipment and more easier to install.

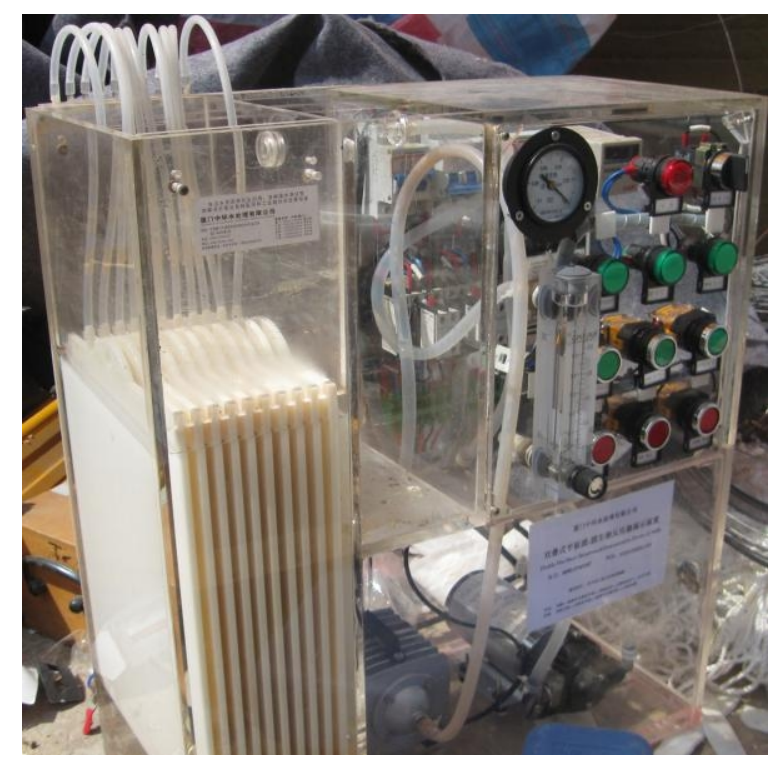

Fig. 7 Membrane biological reactor

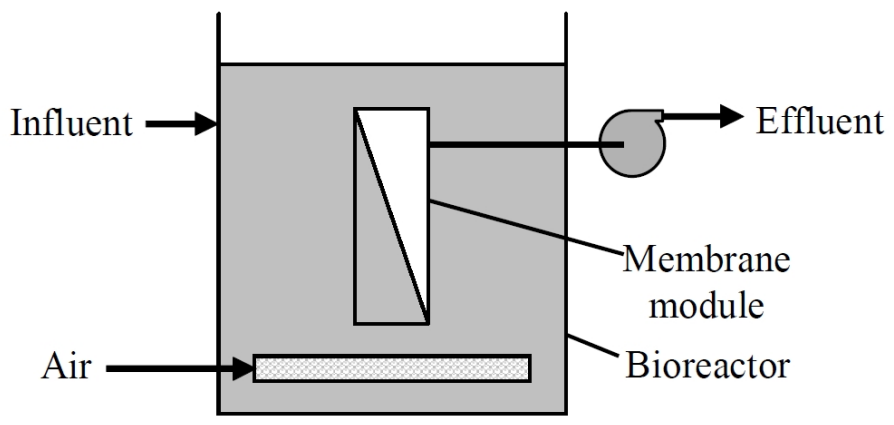

Fig.8 Schematic diagrams of basic MBR configurations: MBR with immersed membrane module[5]

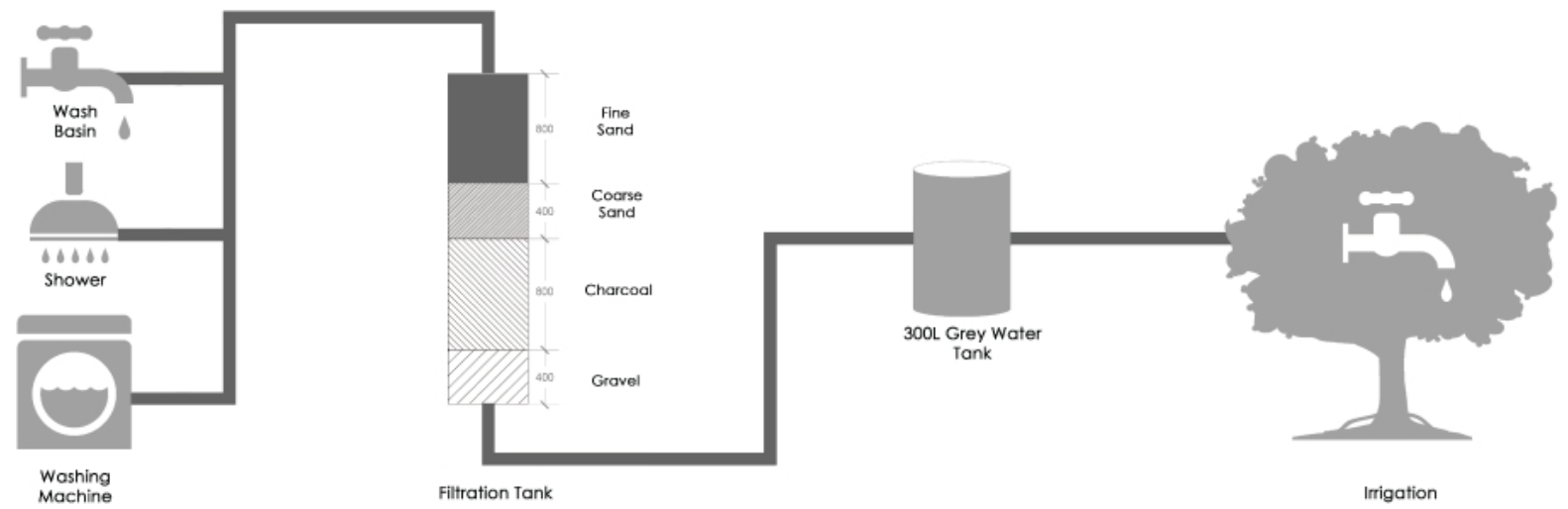

Fig. 9 Team NUS's grey water treatment

Rainwater Collection System. Rainwater on the sloping roof gathering in one place was guided and collected to the rainwater tank after being filtered in Sunny Inside. The collected water finally went into a 500L iron tank with inlet, outlet, overflow port, drain port, and inspection door. Water in the tank is used to water the flowers. 
Irrigation and Drainage Systems. Water for irrigation was from rainwater tank and grey water tank, which needed pumps to be pumped out. The head of delivery of the pumps was determined by the length of irrigation pipes and the height of spray nozzles. There are two types of spray nozzles in Sunny Inside, one for square garden and the other for oblong garden. Magnetic valves controlled which garden to be irrigated. Drainage system drained dirty wastewater from dishwasher, clotheswasher, and the washbasin in kitchen. Drainage pipes used gravity to guide water from higher place to the main drainage pipe which was the lowest place of these pipes.

\section{Conclusions}

This paper discusses the design of water and wastewater systems in Sunny Inside and other highly energy-efficient houses in SDC. All examples show that water and wasterwater systems in a highly energy-efficient, environmentally friendly house were complicated and were related to many other things such as the height of ceiling, position of garden, and so on. It is not a single work can be done independently. In addition to this, there are so many details need to be remembered and remarked. In $\mathrm{SD}$, details determine success or failure.

\section{Acknowledgement}

We would like to express our gratitude to all the students and teachers for their efforts in 2013 Solar Decathlon China competition to design, build, and transport Sunny Inside. The research is supported by National Natural Science Foundation of China (51308481), and also supported by Natural Science Foundation of Fujian Province, China (2013J05082).

\section{References}

[1] Wigginton, N.S., Solar Decathlon 2011. Science, 2011. 334(60-61): p. 1350-1350.

[2] Hepbasli, A. and Y. Kalinci, A review of heat pump water heating systems. Renewable and Sustainable Energy Reviews, 2009. 13(6-7): p. 1211-1229.

[3] Harris J, Neme C, Calwell C. Residential heat pump water heaters: energy efficiency potential and industry status. Prepared for Natural Resources Defense Council, November 2005. http://www.energystarpartners.net/ia/Water_heaters/Documents/VEIC_HPWHfinalreport_Nov2005 .pdf [Access date: January 27, 2008].

[4] Ng, A.N.L. and A.S. Kim, A mini-review of modeling studies on membrane bioreactor (MBR) treatment for municipal wastewaters. Desalination, 2007. 212(1-3): p. 261-281.

[5] G. Tchobanoglous, F.L. Burton and H.D. Stensel, Wastewater Engineering: Treatment and Reuse, McGraw-Hill, Boston, 2004, pp. 854-865. 